\title{
ANGIOGRAPHIC FINDING OF AN ANEURYSM AND ARTERIOVENOUS MALFORMATION IN THE POSTERIOR CRANIAL FOSSA IN A CASE OF SUBARACHNOID HAEMORRHAGE
}

BY

\author{
R. MYLES GIBSON and A. N. da ROCHA MELO
}

From the Department of Surgical Neurology, the Royal Infirmary, Edinburgh

Intracranial arteriovenous malformations are usually found in the cerebral hemispheres. They are not true tumours, but vascular malformations of congenital origin. Arteriovenous malformations in the posterior fossa are much less common than those involving the cerebral hemisphere, but such malformations in the posterior fossa are an occasional source of spontaneous intracranial haemorrhage. Their symptomatic and radiological diagnosis has been fully described by Logue and Monckton (1954). Saccular aneurysm on the arterial tree in the posterior fossa is also recognized as a cause of spontaneous intracranial bleeding and in recent years this has been fairly frequently reported (Spatz and Bull, 1957; DeSaussure, Hunter, and Robertson, 1958). Spatz and Bull (1957) have recorded a high incidence of positive findings on the vertebral basilar tree in cases of subarachnoid haemorrhage in which no lesion could be demonstrated on carotid angiography. In 16 of their 60 such cases ( $26 \%)$ vertebral angiography demonstrated a lesion capable of producing, and assumed to be responsible for, the spontaneous subarachnoid haemorrhage. Eight of the lesions were aneurysms, and the remaining eight arteriovenous malformations. Three of these 16 patients were cured by total excision of the lesion. Further, Logue (1958) described six cases of aneurysm on the vertebral basilar system successfully treated by operation. Poppen and Bassett are reported (DeSaussure et al., 1958) as having successfully tackled three aneurysms on the posterior inferior cerebellar artery and one on the anterior inferior cerebellar artery. The increasing awareness of the possibility of successful surgical attack on these lesions located in the posterior fossa causing spontaneous subarachnoid haemorrhage has stimulated an increasing use of vertebral angiography in cases of subarachnoid haemorrhage with negative carotid angiography. In the course of investigating such a case in the Department of Surgical Neurology in the
Royal Infirmary of Edinburgh, angiography demonstrated both an arteriovenous malformation and an aneurysm on the vertebral basilar tree. The association of these anomalies in the supratentorial region is recognized (Paterson and McKissock, 1956; Potter, 1955).

In Paterson and McKissock's large series of 110 cases of intracranial vascular malformation, four patients were thought to have a true intracranial aneurysm in addition to an arteriovenous malformation. In only one of these was this combined pathology in the posterior fossa and the diagnosis was a post-mortem one. The patient died from the ruptured aneurysm which was found at necropsy to be situated on the right posterior inferior cerebellar artery with the angioma in this case lying in the left cerebellar hemisphere. The interest and rarity of the angiographic finding in the case to be described was thought to merit its recording.

\section{Case Report}

Mr. J. R., a 51-year-old chemical plumber, was admitted to the Royal Infirmary of Edinburgh on September 20, 1956. He had previously enjoyed good health and gave no history of previous illness or syndromes suggestive of intracranial bleeding.

Following a game of golf, 24 hours before admission, he bent down to undo his shoes, was seized with severe bifrontal headache, felt nauseated and vomited. He was never unconscious. The headache persisted.

On admission to hospital he was found to be alert and cooperative, complaining of bifrontal headache. $\mathrm{He}$ was orientated. The pupils were normal in size and ligh reaction. There was mild stiffness of the neck and a positive Kernig sign. Subarachnoid haemorrhage was confirmed by lumbar puncture. The blood pressure was $170 / 110 \mathrm{~mm}$./Hg. No bruit could be heard on listening to the skull but interestingly enough marked pulsation could be felt over the region of the left mastoid process. This is noteworthy since in such cases, as Potter (1955) remarked, "increased extracranial vascularity is an uncommon feature and is quite unreliable as a diagnostic aid in view of its rarity". 


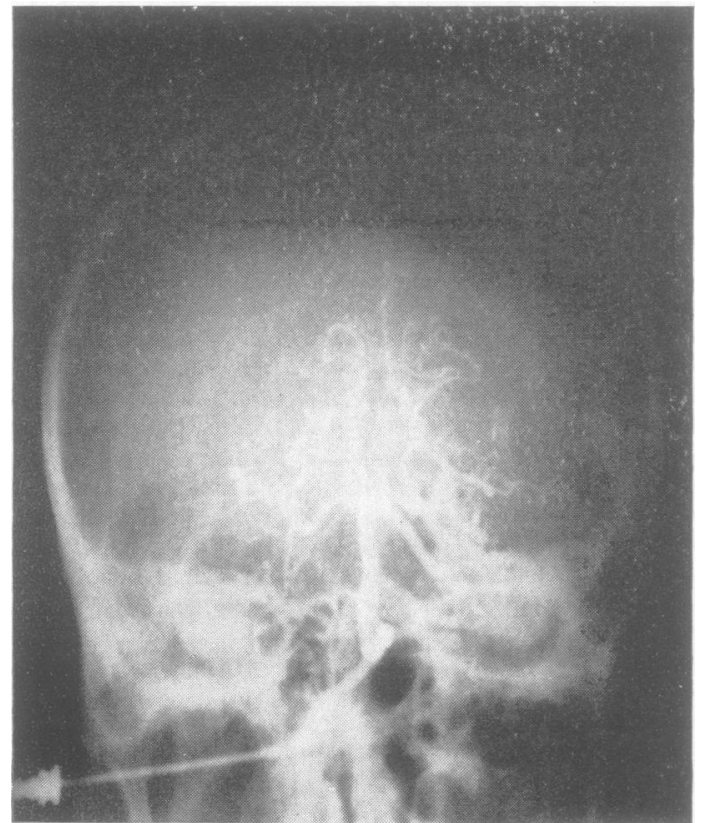

FIG. 1.-Anterio-posterior view of vertebral angiogram showing good filling of the basilar arterial tree. The left superior cerebellar and the left anterior inferior cerebellar branches are enlarged and both take part in the supply of the arteriovenous anomaly situated in the left cerebello-pontine angle.

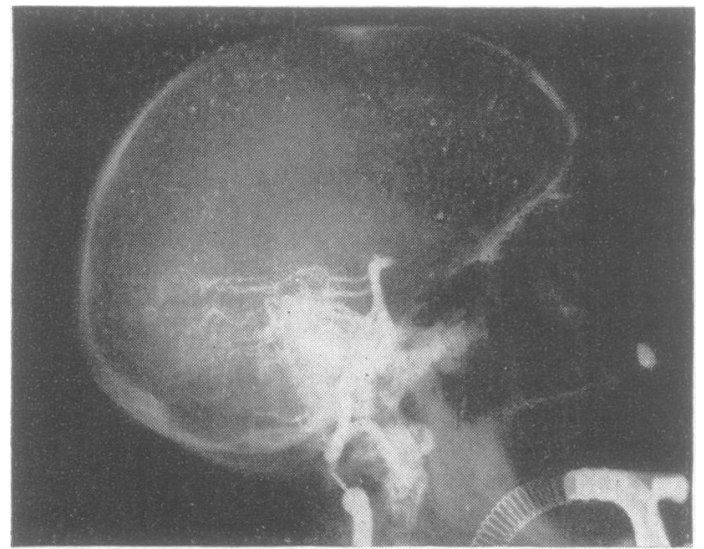

Fig. 2.-The lateral view of the vertebral angiogram shows clearly the aneurysm, close to the terminal bifurcation of the basilar artery. The sac projects upwards and forwards from the distal aspect of the origin of the enlarged left superior cerebellar artery from the basilar trunk. The proximal part of the sac lies in front of the origin of the posterior cerebral artery.

A day later he was found to be slightly drowsy and to be mildly confused. His period in hospital coincided with the Edinburgh Festival. He was being examined on a thundery afternoon and on being asked where he was he answered, after a peal of thunder, "Ah! at the Tattoo!"
Stereo films of the skull were obtained and an E.E.G.으 performed. No abnormalities were shown.

Four days after his episode of haemorrhage he was submitted to carotid angiography, but no pathologicalō findings could be demonstrated. A good cross circulation was shown.

Vertebral angiography was carried out three days later. The right vertebral artery was punctured by the Maslowski method (Maslowski, 1955) and satisfactory filling of the right vertebral artery and the basilar artery and its intracranial branches was obtained. The basilar. artery was somewhat larger than usual and its left superior cerebellar branch and the left anterior inferior cerebellar artery dilated. These two vessels were seen to take par in the supply of a moderate sized arteriovenous anomaly음 situated in the region of the cerebello-pontine angle $\bar{\Phi}$ The venous drainage was relatively complicated and extended upwards to the straight sinus and laterally to the lateral sinus. Other dilated veins were seen in thes suboccipital region, presumably representing some $\overrightarrow{0}$ drainage through the mastoid emissary veins. In addition there was a moderate sized saccular aneurysm close $\vec{\omega}$ to the terminal bifurcation of the basilar artery. The saco projected upwards and forwards from the distal aspect of the origin of the enlarged left superior cerebellar artery? from the basilar trunk, and the proximal part lay in front of the origin of the posterior cerebral artery.

No surgical treatment was undertaken and the patientin was slowly and progressively mobilized and rehabilitate. When seen as an out-patient three months after subarachnoid haemorrhage, he was well and had already. returned to work. He suffered an occasional headacipe if he unduly exerted himself or tried to do too much work Physical examination revealed no abnormality apart frefo the moderately increased pulsation in the left mastaf region noted at the time of his original admissies $\overrightarrow{3}$ However, 20 months after this first episode he was? admitted to hospital in deep coma with a recurrent subarachnoid haemorrhage from which he died.

\section{Summary}

A case of spontaneous subarachnoid haemorrhage气 in a man aged 51 is described. Investigation bye carotid and vertebral angiography revealed an $\overrightarrow{\vec{\sigma}}$ arteriovenous malformation and a saccular aneurysm in the posterior fossa. The rarity of this condition is commented upon. The dangerous nature of such? anomalies is illustrated by the fact that this patient died from a recurrent haemorrhage 20 months after his first attack.

We wish to thank Professor Norman N. Dott and Mr. F. John Gillingham for permission to record this case.

\section{REFERENCES}

DeSaussure, R. L., Hunter, S. E., and Robertson, J. T. (1958) $J$. Neurosurg., 15, 385 .

Logue, V. (1958). J. Neurol., Neurosurg. Psychiat., 21, 66. , and Monckton G. (1954). Brain, 77, 252.

Maslowski, H. (1955). Brit. J. Surg., 43, i.

Paterson, J. H., and McKissock, W. (1956). Brain, 79, 233.

Potter, J. M. (1955). Ann. roy. Coll. Surg. Engl., 16, 227.

Spatz, E. L., and Bull, J. W. D. (1957). J. Neurosurg., 14, 543. 